(MINI REVIEW)

\title{
Neurotransmitters and nitric oxide are released in various brain areas according to ultradian and infradian rhythms
}

\author{
Athineos Philippu * \\ Department of Pharmacology and Toxicology, University of Innsbruck, Austria.
}

Publication history: Received on 13 November 2020; revised on 20 November 2020; accepted on 21 November 2020

Article DOI: https://doi.org/10.30574/wjarr.2020.8.2.0430

\begin{abstract}
The push-pull superfusion technique was used to investigate release of endogenous neurotransmitters and nitric oxide in various brain regions. The transmitters catecholamines, histamine, GABA, glutamate, as well and nitric oxide are released according to ultradian rhythms which generate fluctuations of vegetative functions such as blood pressure and arousal. More frequent infradian oscillations of neurotransmitter and nitric oxide release fates are implicated in mutual interneural control.
\end{abstract}

Keywords: Push-pull superfusion; Ultradian and infradian oscillations; Neurotransmitter release; Nitric oxide; Blood pressure; arousal

\section{Introduction}

As determined by chronobiology, ultradian rhythms are periodicities repeated throughout a 24-hour day, whereas infradian rhythms last less than one hour. Meanwhile, several brain functions that control peripheral systems have been described which vary according to ultradian fluctuations. However, to get an insight into the mechanisms involved in the processing of these brain functions, more than their mere description is necessary. The knowledge of the neurons and their transmitters involved in these processes is indispensable for understanding how brain is working, but experimental approach is demanding.

An outstanding time resolution and very sensitive methods are needed to record rapid changes in the release rates of endogenous neurotransmitters from their neurons in very short time periods as is the case in ultradian and infradian rhythms. Because of these prerequisites, the push-pull superfusion technique (PPST) has been used in almost all investigations. In cats, the time resolution of PPST is as low as $10 \mathrm{~s}$, in small animals like rats less than 2 min (for technical details see 1-4). Moreover, recoveries must be constant up to $20 \mathrm{~h}$. In fact, no other approach fulfils these prerequisites for the quantitative determination of neurotransmitters released in the synaptic cleft. Other approaches such as microdialysis are not suitable, because glial cells around the probe modify after few hours the recovery of released transmitters and other compounds. Moreover, larger molecules do not permeate easily through the semipermeable membrane of the probe $[5,6]$

Using the PPST it has been shown that in the cat posterior hypothalamus the release rates of the catecholamines dopamine, noradrenaline and adrenaline are not constant over time but they vary according a bimodal pattern, since peaks of high release rates are separated from each other by peaks of low amine concentrations pointing to phasic changes in the release rates of all three catecholamines. In six hours, five peaks of increased release rates appear. Thus, the time interval between two adjacent peaks is about $70 \mathrm{~min}$ showing that, in the cat hypothalamus, the three catecholamines are released according to an ultradian rhythm [7].

\footnotetext{
* Corresponding author: Dr. Athineos Philippu

Department of Pharmacology and Toxicology, University of Innsbruck, Austria.
} 
In other brain areas of cats and rats, catecholamines are also released according to ultradian rhythms. When perfusates are continuously collected in time periods of $10 \mathrm{~min}$, in the nucleus of the solitary tract (NTS) of cats the release of catecholamines oscillates with a frequency of approximately one cycle per hour. Moreover, when superfusates are collected every $2.5 \mathrm{~min}$ instead of $10 \mathrm{~min}$ an additional ultradian rhythm appears with a frequency of one cycle per 10 min [8]. In the locus coeruleus, dopamine, noradrenaline and adrenaline are liberated according ultradian rhythms of $37 \pm 2,52 \pm 4$ and $36 \pm 2 \mathrm{~min}$, respectively [9]. Similarly, in the posterior hypothalamus of conscious, freely moving rats, the three catecholamines are released according to an ultradian rhythm of 92-99 min [10].

These fluctuations of catecholamine concentrations in the synaptic cleft are the reason for ultradian alterations of brain activity and consequently of neurovegetative functions such as central blood pressure control and arousal. Fluctuations of peripheral catecholamine levels are due to the abovementioned fluctuations in the catecholamine release in the brain [11]. It has also been shown that the catecholaminergic neurons of hypothalamus, nucleus of the solitary tract, locus coeruleus are strongly involved in central regulation of blood pressure $[12,13]$. Moreover, striatal dopamine levels fluctuate in synchrony with ultradian activity cycles [14], while the dopaminergic neuromodulation of the monkey visual cortex greatly influences both spontaneous and visually-evoked neural activity [15]. Very likely, the fluctuating transmitter concentrations in the synaptic cleft lead to fluctuating stimulation of postsynaptically located autoreceptors and hetero-receptors, thus changing periodically the activity of peripheral sympathetic system and suprarenals [12,13] and the levels of peripheral catecholamines fluctuate rhythmically. The release of other neurotransmitters, such as GABA [16], glutamate [17], histamine [18-20] and nitric oxide [3, 22, 22] also fluctuates according to similar ultradian rhythms. Findings are recapitulated in Table 1.

In the hypothalamus, the similar periodicities of transmitter release with those of autonomic, cardiovascular, and neuroendocrine rhythms provide evidence for their physical coupling within this brain region (Shannahoff-Khalsa and Philippu, to be published).

Besides ultradian rhythms, infradian oscillations $[10,20]$ have also been described in experiments, in which samples were continuously collected every $2.5 \mathrm{~min}$. Obviously, they reflect interneural signals related to stimulation of autoreceptors and herewith are associated with mutual regulations of neuronal activity (Table 1).

Interestingly, ultradian and infradian oscillation have been found in conscious and anaesthetized animals as well (Table 1).

Please the following four lines should appear below the Table!Ultradian rhythms in min. Samples were collected in time periods of 10 min or *2.5 min. NAc nucleus accumbens, PH posterior hypothalamus, AH anterior hypothalamus, NTS nucleus of the solitary tract, LC locus coeruleus, MAN medial amygdaloid nucleus, MB mammillary body, DA dopamine, NA noradrenaline. A adrenaline, HI histamine. GLU glutamate, an. anaesthetized, co. conscious (modified from Philippu, 2016).

Table 1 Ultradian and infradian rhythms of neurotransmitters and nitric oxide released in various brain regions

\begin{tabular}{|c|c|c|c|c|c|c|c|c|}
\hline & Animal Species & NAc & $\mathrm{PH}$ & $\mathrm{AH}$ & NTS & $\mathrm{LC}$ & MAN & MB \\
\hline NO & an. rat & 24 & & & & & & \\
\hline DA & an. cat & & 70 & 70 & $6010^{*}$ & 37 & & \\
\hline NA & an. cat & & 70 & 70 & $6010^{*}$ & 52 & & \\
\hline A & an. cat & & 70 & 70 & $6010^{*}$ & 36 & & \\
\hline HI & an. cat & 60 & & & & & $13519 *$ & $90 \quad 19 *$ \\
\hline $\mathrm{HI}$ & an. rat & & 115 & & & & & \\
\hline HI & co. rabbit & 70 & 70 & & & & & \\
\hline GABA & co. rat & & 65 & & & & & \\
\hline GABA & an.cat & 70 & 70 & & & & & \\
\hline GLU & co. rat & & 45 & & & & & \\
\hline
\end{tabular}

Ultradian rhythms in min. Samples were collected in time periods of 10 min or *2.5 min. NAc nucleus accumbens, PH posterior hypothalamus, AH anterior hypothalamus, NTS nucleus of the solitary tract, LC locus coeruleus, MAN medial amygdaloid nucleus, MB mammillary body, DA dopamine, NA noradrenaline. A adrenaline, HI histamine. GLU glutamate, an. anaesthetized, co. conscious (modified from Philippu, 2016). 


\section{Conclusion}

Several neurotransmitters and the neuromodulator nitric oxide are released according to ultradian and infradian rhythms in various brain regions, which reflect oscillating neuronal activity. These rhythmic changes are the reason for the ultradian alterations of the peripheral neurovegetative system.

\section{Compliance with ethical standards}

\section{Acknowledgments}

This work was supported by the Deutsche Forschungsgemeinschaft (DFG) and the Fonds zur Förderung der Wissenschaftlichen Forschung (FWF)

\section{References}

[1] Philippu A. Use of push-pull cannulae to determine the release of endogenous neurotransmitters in distinct brain areas of anaesthetized and freely moving animals. In: Ed. C.A. Marsden. Measurement of Neurotransmitter Release. Chichester: John Wiley. 1984; 3-37.

[2] Kraus MM, Philippu A. Use of push-pull superfusion technique for Identifying neurotransmitters involved in brain functions: achievements and perspectives.

[3] Kraus MM, Philippu A. Involvement of neurotransmitters in mnemonic processes, response to noxious stimuli and conditioned fear - a push-pull superfusion study. In: Ed. A. Philippu. In vivo Neuropharmacology and Neurophysiology. New York: Springer Science+Business Media. 2017; 237- 52.

[4] Hornick A., Philippu A. Principles of Stereotaew York: Springer Science+Business Media. 2017; 3-14.

[5] Paulsen RE, Fonnum F. Role of glial cells for the basal and ca2+-dependent k+-evoked release of transmitter amino acids investigated by microdialysis. J. Neurochem.1989; 52: 1823-29.

[6] Vasicek TW, Jackson MR, Poseno TM, Stenken JA. In Vivo Microdialysis Sampling of Cytokines from Rat Hippocampus: Comparison of Cannula Implantation Procedures. ACS Chem. Neurosci. 2013; 4: 737-46.

[7] Philippu A, Dietl H, Sinha JN. In vivo release of endogenous catecholamines in the hypothalamus. NaunynSchmiedeberg's Arch. Pharmacol. 1979; 308: 137-42.

[8] Lanzinger I, Kobilansky C, Philippu A. Pattern of catecholamine release in the nucleus tractus solitarii of the cat. Naunyn-Schmiedeberg's Arch. Pharmacol. 1989; 339: 298-01.

[9] Singewald N, Schneider Ch, Philippu A. Effects of neuroactive compounds, noxious and cardiovascular stimuli on the release of amino acids in the rat locus coeruleus. Neurosci. Lett. 1994; 180: 55-58.

[10] Dietl H, Prast H, Philippu A. Pulsatile release of catecholamines in the hypothalamus of conscious rats. NaunynSchmiedeberg's Arch. Pharmacol. 1993; 347: 28-33.

[11] Levin BE, Goldstein A, Natelson BH. Ultradian rhythm of plasma noradrenaline in rhesus monkeys. Nature. 1978; 272: 164-66.

[12] Philippu A. Regulation of blood pressure by central neurotransmitters and neuropeptides. Rev. Physiol. Biochem. Pharmacol. 1988; 111: 1-115.

[13] Singewald N., Philippu A. Involvement of biogenic amines and amino acids in central blood pressure regulation. Trends Pharmacol. Sci. 1996; 17: 356-63.

[14] Blum ID, Zhu L, Moquin L, Kokoeva MV, Gratton A, Giros B, Storch KF. A highly tunable dopaminergic oscillator generates ultradian rhythms of behavioral arousal. Elife. 2014; 29; 3: e05105. 2014; 3: e05105.

[15] Zaldivar D, Goense J, Lowe SC, Logothetis NK, Panzeri S. Dopamine Is signaled by mid-frequency oscillations and boosts output Layers visual Information in visual cortex. Curr. Biol. 2018; 28: 224-235.

[16] Dietl H, Philippu A. In vivo release of endogenous gamma-aminobutyric acid in the cat hypothalamus. NaunynSchmiedeberg's Arch. Pharmacol. 1979; 308: 143-147. 
[17] Singewald N, Chen F, Guo LY, Philippu A. Ionic and haemodynamic chan ges influence the release of the excitatory amino acid glutamate in the posterior hyาpoาthalamus. Naunyn-Schmiedeberg's Arch. Pharmacol. 1995; 352: 620-625.

[18] Philippu A, Hanesch U, Hagen R, Robinson R. Release of endogenous histamine in the hypothalamus of anaesthetized cats and conscious, freely moving rabbits. Naunyn-Schmiedeberg's Arch. Pharmacol. 1982; 321: 282-286.

[19] Prast H., Saxer A., Philippu A. Pattern of in vivo release of endogenous histamine in the mamillary body and the amygdala. Naunyn-Schmiedeberg's Arch. Pharmacol. 1988; 337: 53-57.

[20] Prast H., Dietl H., Philippu, A. Pulsatile release of histamine in the hypothalamus of conscious rats. J. Auton. Nerv. System. 1992; 39: 105-110.

[21] Prast H, Hornick A, Kraus MM, Philippu, A. Origin of endogenous nitric oxide released in the nucleus accumbens under real-time in vivo conditions. Life Sci. 2015; 134: 79-84.

[22] Philippu A, Kraus MM, Push-pull superfusion: A technique for investigating involvement of neurotransmitters in brain function, in: Ed. A. Philippu. In Vivo Neuropharmacology and Neurophysiology. New York: Springer Science+Business Media. 2017; 209 - 236. 